\title{
Mein Patient, ein kleiner kroatischer Prinz
}

_ Als sein Haus im Krieg zerstört worden war, war der Kroate nach Deutschland gezogen und hatte ein kleines Grundstück am Rande der Stadt gefunden, wo die Weizenfelder beginnen. In meiner Praxis war er nie als besonders redseliger Patient aufgefallen. Einmal allerdings gab es doch etwas Schönes, was er mir unbedingt erzählen wollte: Jeden Tag kam ein kleiner Fuchs zu ihm aufs Grundstück und betrachtete ihn kritisch aus sicherer Entfernung.

Ich konnte es kaum glauben! Das war ja wie bei de Saint-Exupéry, als der Fuchs dem kleinen Prinzen begegnet und ihn bittet, ihn zu zähmen. Ich erzählte meinem Patienten davon, aber ihm was das Werk unbekannt. Ich versuchte, ihm diesen Teil der Geschichte trotz einer gewissen Sprachbarriere nachzuerzählen, doch bei dem Wort „zähmen" stieß ich an die Grenze der ge- nauen Erklärung - obwohl das doch der Kern des Ganzen ist.

Es half also nichts, der „Kleine Prinz“ musste auf kroatisch her, als Überraschung natürlich. Mal überlegen ... war da nicht diese kroatische Studentin, der ich strikt verboten hatte, in ihre Heimat

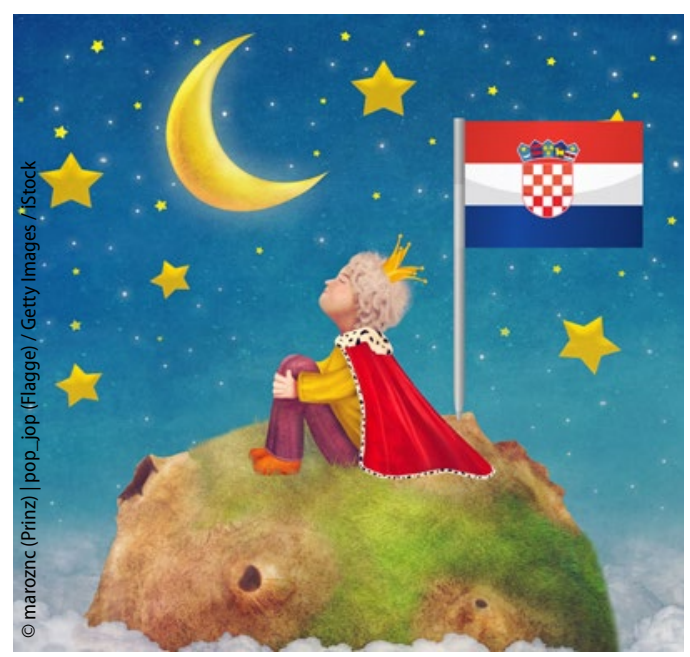

zu fahren, da ich die Reise für eine Patientin mit Endokarditis viel zu anstrengend empfand? Als die mein Sprechzimmer verlassen hatte, konnte ich ihr noch von hinten ansehen, dass sie gegen meinen Rat fahren würde.

Ich mailte sie also an und bekam nach drei Tagen ein Telefonat, das ich sofort durchstellen ließ. Die junge Frau stand just in Zagreb vor dem Buchladen und wollte wissen, ob ich noch interessiert sei. Am Ende des Sommers, als ich ihr in meiner Praxis eine komplette Genesung attestieren konnte, übergab sie mir dann das Buch „Mali Princ“, das ich ihrem Landsmann schenkte.

Wie heißt es so schön in dem Buch? Man sieht nur mit dem Herzen gut. Das Wesentliche ist für die Augen unsichtbar. Oder: „Čovjek dobro vidi samo srcem. Ono birno ne vidi se očima.“

Dr. Luise Hess, Darmstadt

\section{Lahm vor lauter Enkelschmerzen}

Fremdsprachenkenntnisse sind nie verkehrt - und helfen bisweilen auch bei einheimischen Patienten. So wurde ich im Notdienst einmal von einer akzentfrei deutsch sprechenden Patientin angefordert, die meinte, ihr Enkel schmerze, sie könne nicht mehr laufen. Einfach so, ohne Unfall.

Mir war schleierhaft, was sie meinte. Ein Kind konnte wohl nicht betroffen sein, schließlich war die Frau selbst beim Laufen beeinträchtigt. Immerhin grenzte dieses Beschwerdebild die Körperregion ein wenig ein. Ich kannte den Be- griff „Onkel“ als Bezeichnung für Zehen, außerdem das englische Wort „ankle“, das ja so ähnlich klingt.

Da meine jahrelange Erfahrung mich lehrte, bei unklaren Situationen lieber hinzufahren und mir selbst einen Eindruck zu machen, statt mich auf lange und verwirrende Diskussionen einzulassen, stand ich bald einer recht beleibten, im Sessel sitzenden Frau gegenüber, die auf ihr Bein zeigte. Die Untersuchung der infrage kommenden Gelenke zeigte schnell, dass tatsächlich der Knöchel Beschwerdeursache war, wahrscheinlich überlastungsbedingt nach einer längeren Stadtbesichtigung.

Danach wollte ich noch meine Neugier bezüglich der anatomischen Bezeichnung stillen. Es war der Frau unverständlich, wieso ich nicht gleich am Telefon gewusst hatte, was sie gemeint hatte. Sie war an der niederländischen Grenze aufgewachsen - und dort ist „Enkel“ offenbar ein gängiger Begriff für den Knöchel. Die sprachliche Verwandschaft zum englischen Wort war meiner Patientin überhaupt nicht bewusst.

Dr. Andrea Linsel, Lüneburg 